\title{
Bridging the Skills Gap of Workers in Industry 4.0 by Human Performance Augmentation Tools - Challenges and Roadmap
}

\author{
Eric Ras \\ Luxembourg Institute of \\ Science and Technology, \\ 5 Avenue des Hauts- \\ Fourneaux, \\ L-4363 Esch-sur-Alzette, \\ Luxembourg \\ eric.ras@list.lu
}

\author{
Fridolin Wild \\ Department of Computing \\ and Communications Tech- \\ nologies, \\ Oxford Brookes University, \\ Oxford OX33 1HX, \\ United Kingdom \\ wild@brookes.ac.uk
}

\author{
Christoph Stahl \\ Luxembourg Institute of \\ Science and Technology, \\ 5 Avenue des Hauts- \\ Fourneaux, \\ L-4363 Esch-sur-Alzette, \\ Luxembourg \\ christoph.stahl@list.lu
}

\author{
Alexandre Baudet \\ Luxembourg Institute of \\ Science and Technology, \\ 5 Avenue des Hauts- \\ Fourneaux, \\ L-4363 Esch-sur-Alzette, \\ Luxembourg \\ alexandre.baudet@list.lu
}

\begin{abstract}
Industry 4.0 is a coordinated push for automation in Smart Factories and other Cyber-Physical Systems (CPS). The increasing complexity of frequently changing production environments challenges shop floor workers to perform well. The tasks they work on are getting less routine and ask for continuous knowledge and skills development. For example, the skills portfolio of workers likely requires improved higher-order thinking and decisionmaking skills. A wide range of research and development efforts already today sets focus on different areas of workplace learning, including performance appraisals, pedagogy and education, technology, and business economics. Bridging the skills gap, however, requires novel user-facing technologies - such as Augmented Reality (AR) and wearables - for human performance augmentation to improve efficiency and effectiveness of staff delivered through live guidance. AR branches out beyond mobile apps with 3Dobject superimposition for marketing purposes to rather complex use cases delivered by a rapidly growing innovation ecosystem of hard- and software providers collaborating closely with R\&D organisations. This paper provides a first shared vision on how AR can tackle four different challenges related to handling complexity in a CPS environment: develop intelligent assistance systems for learning and performance assessment at the workplace, adapt job profiles accordingly, and last but not least to address also the issue of work-life balance. The paper concludes with an outline of a research roadmap.
\end{abstract}

\section{CCS CONCEPTS}

Human-centered computing $\rightarrow$ Interaction design; Ubiquitous and Mobile Computing

Permission to make digital or hard copies of all or part of this work for personal or classroom use is granted without fee provided that copies are not made or distributed for profit or commercial advantage and that copies bear this notice and the full citation on the first page. Copyrights for components of this work owned by others than the authors must be honored. Abstracting with credit is permitted. To copy otherwise, or republish, to post on servers or to redistribute to lists, requires prior specific permission and/or a fee. Request permissions from permissions@acm.org. PETRA '17, June 21-23, 2017, Island of Rhodes, Greece

Copyright is held by the owner/author(s). Publication rights licensed to ACM. ACM 978-1-4503-5227-7/17/06_..\$15.00

DOI: http://dx.doi.org/10.1145/3056540.3076192

\section{KEYWORDS}

Performance Augmentation, Augmented Reality, Industry 4.0, Job Profiles

\section{INTRODUCTION}

The fourth industrial revolution is on its way: a multitude of national initiatives [1] is currently implementing what is called Industry 4.0 (also known as: Industrie 4.0, DE; Smart Industry, NL; Catapults, UK; or Industrie du Futur, FR): a coordinated push for automation, big data, and internet-of-things in the smart factory and other cyber-physical systems (CPS). This shift causes major disruption in the job market with the OECD predicting that at least $9 \%$ of all jobs could be automated already today [2]. Augmented Reality (AR) is considered one of the key disruptive technologies in the mix catering for Industry 4.0 [3]. Gaining momentum over recent years, AR branches out now beyond mobile apps with 3D-object superimposition for marketing purposes to rather complex use cases delivered by a rapidly growing innovation ecosystem of hard and software providers collaborating closely with R\&D departments.

Beyond applications in manufacturing, construction, medicine, energy, or sports (see IEEE Standard Association ${ }^{1}$ ), the most consequential opportunity is probably to use AR technologies at scale for training and professional development in industry, tackling the skills gap left behind by advances in automation that is not yet matched by programs for knowledge capture and boundarycrossing organisational learning (as in AI-supported knowledge management and change management).

At the same time, talent continues to be rare and, consequently, many positions for skilled jobs remain unfilled. In the UK alone, this skills gap has widened so far that now one in four positions "go unfilled due to skills shortage" [4, 5]. Spöttl et al. [6] explains

${ }^{1}$ http://standards.ieee.org/innovate/ar/future.html 
that the number of jobs in this sector is to be expected to stay stable and even to grow by $30 \%$; the classical jobs of professionals in production have very good chances of future employment.

Looking deeper into which types of skills are sought after, this reveals that it is not only about classic professional skills such as operating and maintaining machinery, but rather a model ' $\mathrm{T}$ ', combining deep professional skills with broad horizontal ones (such as time management, team leadership, or critical thinking, see, e.g., $[5,7]$. Needs are wider than just skills, there is also a well-being component, supporting ergonomic and healthy behaviour at the workplace. The European Commission reflects this in the recent communique on a new skills agenda for Europe [8], thereby proposing a 10 point action plan including to review the key competences framework for lifelong learning and including the upgrade of vocational education and training (to make it a first choice).

A wide range of research and development effort has focussed on different areas of workplace learning: Performance appraisal, pedagogy and education, technology, business economics. These existing approaches, however, are ill-equipped to tackle the challenges of an Industry 4.0 and help with bridging the skills gap at scale with the help of novel user-facing technologies such as AR, wearables, and the like - with the help of performance augmentation technologies.

It is unlikely that Industry 4.0 itself will go beyond building AR user interfaces for control of machines, and the education and training aspect of augmenting human performance will not receive the attention required. If left uncoordinated, existing efforts will be more resource consuming and less likely to succeed.

\section{FOUR CHALLENGES}

By digitizing manufacturing processes, products can be created with increased flexibility, radically improved productive efficiency, and cost-effective low volume manufacturing. Across Europe, this change is often referred to as 'Industry 4.0'. It describes the joint introduction of cyber-physical systems, the Internet of Things, Internet of Services, and Smart Factories into the manufacturing process [9].

In the following, we will discuss four resulting challenges regarding the consequences of Industry 4.0 for the workforce.

\subsection{Industry 4.0 - A Challenge of Complexity}

This fourth innovation wave in production impacts on the full value chain from logistics over design and production to after sales services. This on-going upgrade in industry requires changes to processes on all levels of automation (including I/O level, steering and control, and enterprise resource planning). Novel cyberphysical systems (CPS) produce Big Data and require the utilisation of that data to improve work of humans and automation by machines. The complexity of systems to be configured, operated, and maintained is increasing, because of:

- Horizontal integration of the value network

- Vertical integration of networking production systems

- Digital continuity of engineering across whole value chain

- Dynamic adaptation of business and engineering processes
- Data-driven planning and steering of production processes

Challenge 1 (complexity): The workforce needs to understand the underlying processes, their dependencies, and develop the knowhow needed for collecting and utilising data and leveraging digitisation in the intelligent production of smart products with flexible lot sizes.

In order to manage complexity, professionals need to have adequate planning and explanation models as a basis coupled with intelligent assistance systems and data analysis approaches, which support complex problem solving in the Industry 4.0 context. However, such solutions are still in infancy state.

\subsection{Intelligent assistance with Augmented Reality (AR) for Task Performance Augmentation}

To shift from operating a system to steering and regulation a production system, the aim is that professionals become more flexible in solving complex problems in the smart factory (German Federal Ministry for education and research [10]. Therefore and together with key research institutions, early industrial adopters of Industry 4.0 have started to developed intelligent assistance and training systems using AR.

According to the Lorenz et al. [11], an "[e]ffective training program for specific job-related skills should include both on-the-job instruction (through the use of augmented-reality, for example, or by observing how experienced workers perform a task) and classroom instruction". Learning factories, or learning islands, which are already used for training more classical manufacturing tasks, should be adapted to the need of Industry 4.0 related competences [6].

Obviously, such novel technology as AR is most relevant to Industry 4.0 with smart factories, increasing amounts of advanced robotics, and adaptive manufacturing processes. AR offers potential especially for human performance augmentation: to improve efficiency and effectiveness of staff through extended live guidance. AR is the user interface in human machine collaboration in Industry 4.0. It is a vehicle of introduction and building block for the digitization of manufacturing processes, increased flexibility in product development, radically improved productive efficiency, and cost-effective low volume manufacturing.

Other than Virtual Reality, AR refers to enhancing standard human perception with additional, artificially generated sensory inputs, merging natural and digital offers into a combined, 'augmented' experience. Prominently featuring (but not restricted to) visual senses, AR has given rise to a whole ecosystem of hardand software to produce and deliver such blended offers. Most notably in recent years, Smart Glasses products emerged that use embedded transparent displays to overlay computer graphics onto areas of the field of view, placing content optically into the space of the real environment, creating a very believable super-'reality'. Even though Europe has been leading in AR and is certainly a motor in the development of Industry 4.0, Performance augmentation R\&D is often isolated or focused on isolated aspects such as user interfaces, specific sensors, or generic learning analytics on- 
ly, while Industry 4.0 workplace scenarios often neglect the knowledge elicitation, personal development, and human interaction aspect needed for successful human machine collaboration.

Besides incidental examples (e.g., the ISMAR workshop on advanced manufacturing with AR, see [12], or the IKNOW workshop on Human Computer Interaction Perspectives on Industry 4.0 , see [13]) these groups do not come together on a regular basis.

The work in digital manufacturing requires employees who are both experienced and knowledgeable on the one hand and yet are able to flexibly and continuously (self-)assess their competences, learn and adapt themselves to new developments and requirements at their workplace as industrial production forces changes to the workplace [2].

Today, numerous approaches exist to carry out education, but suitable combinations for workplace learning in Industry 4.0 contexts does not yet exist. But without an adequate performance appraisal strategy and an adequate training of the workforce with suitable educational approaches (e.g., self-regulated, reflective, collaborative, blended learning), there is a risk that workers are excluded from being employed in Industry 4.0 environments and that the expected impact on task performance decreases (i.e., efficiency of production, product diversity and quality).

Challenge 2 (intelligent assistance systems): Standardise, develop, and deploy intelligent assistance systems for live guidance, training by experience, and performance assessment from observation need to follow the changes towards Industry 4.0 with regard to processes with increased degrees of digitisation.

\subsection{Industry 4.0 shifting job profiles}

The workforce of Industry 4.0 needs new skills for changing and upgrading jobs emerging with the introduction of advanced machinery and agile production [14, 15]. Several studies have been conducted to investigate which types of job profiles are mostly impacted by the transformation of Industry 4.0 (e.g., $[2,6,16])$. In the manufacturing sector, jobs with very different activity profiles are impacted by the emerging and expected further change. For example, professionals acting in the operation of production systems will have to acquire radically different skills, with the nature of their tasks changing. Likewise, professionals responsible for networking of production system components will have to establish interconnectivity and interoperability across distributed system components and data streams. The workforce of the production itself is less impacted, see [6].

If some (parts of) jobs might disappear due to Industry 4.0 changes, emerging needs related to Industry 4.0 'collateral' effects would still require non-routine work requiring human expertise (hard or soft), embedded through technological artefacts or not: "the more we depend on technology and push it to its limits, the more we need highly-skilled, well-trained, well-practised people to make systems resilient, acting as the last line of defence against the failures that will inevitably occur" [17].

To develop adaptive expertise, the workforce needs to integrate theoretical and practical knowledge through reflective practice.
Today, there is a gap between task performance appraisal and competence development $[18,19]$.

Many new $21^{\text {st }}$ Century competences are required, e.g., creativity, social intelligence, innovation competence, complex problem solving, as well as domain competences (e.g., configuration of cyber physical systems, maintenance of sensor networks, or knowledge about Internet of Things) [20]. Most notably, the need for creative and social intelligence is significantly increased to support innovation, decision making under uncertainty, and respond to wicked problems (such as, e.g., malfunctioning sensors). For the specific purposes of manufacturing, three main "skill blocks" should be targeted [21]: STEM (Science, Technology, Engineering and Mathematics), MES (Mechanics, Electronics and Software and Manufacturing Technique, and soft skills.

If current white-collar workers will become the designers of Industry 4.0 products, blue-collar workers will become "shadedcollar workers" in order to master cross-domain functions (as a $21^{\text {st }}$ Century competence) when they were used to perform single function (partly or fully handled by machines)[7].

Leading business consultancy and Industry 4.0-technology providing companies like, for example, McKinsey, SAP, Microsoft, German Telekom, or Scheer Consulting already identified the urgent need to advance the education of the workforce to complement the introduction of Industry 4.0 concepts into the production process [22].

The Boston Consulting Group stated that "to prepare for the shifting job requirements of Industry 4.0, companies should work with governmental job agencies to develop a set of capabilities for each profile and design ways to assess individuals' capabilities against these requirements [11].

Challenge 3 (future proofing): Tasks needed in the Industry 4.0 context are more interdisciplinary and combine, for example, elements of mechatronics with design, data analytics, and business administration. The challenge is to revise existing job profiles, build development and appraisal procedures for the existing workforce, and predict which new skills need to be developed in addition to be future proof.

\subsection{Impact on work organisation and work-life balance}

The introduction of Performance Augmentation using AR for Industry 4.0 into daily work processes requires a significant change in the skills profile of the workforce [23, 24]. In the bigger picture, roles of the workforce are changing from being productioncentric to being knowledge- and data-driven, reacting to the change in demand in the associated workplaces.

Intelligent assistance systems bring substantial potential to relief professionals from routine work, while requiring them to focus more on creative, value-adding tasks [25]. Kagermann, Wahlster, and Helbig [25] emphasise that this will likely result in more flexible work organisation, allowing industry professionals to better align private life, work, and education, respectively training. In addition, Performance Augmentation in an Industry 4.0 leads to 
more responsibility for and self-regulation of development of professionals.

Challenge 4 (work life impact): The challenge is to operationalise how socio-technical approaches can be designed to allow grounded participatory design of an interdisciplinary workplace, re-organising lifelong learning in ways that positively impact on the work life balance.

\section{RESEARCH ROADMAP}

In order to address the four challenges, four main research domains have been identified which are expected to contribute to bridging the skills gap of workers in Industry 4.0.

\section{Live Guidance for Advanced Manufacturing}

First, it is essential to elaborate representation standards and recording/enactment technology for expressing procedural guidance for learning and training at the workplace, paying special emphasis to how additional, knowledge-intense rich media and artificial intelligence (deep learning) approaches can be embedded, while interfacing with facilities for defining intended learning outcomes and their according assessment technology. The overwhelming majority of performance augmentation R\&D projects and content collections is agnostic of content model standards, supporting only, if at all, low-level graphics exchange formats (and similar low level content standards). At the same time, several relevant standards working groups exist (IEEE p1589 ARLEM, MPEG ARAF, OGC ARML, and others), but neither have concluded their work, nor reached significant traction. This proliferation, if left uncoordinated, fosters unwanted lock-in effects with high exit costs and increased entry costs for competitors, hindering the development of a healthy technology ecosystem with competing providers and open content in a rapidly growing market.

\section{Performance Analytics: Skills Metrics and Prediction}

Performance is competence in action, providing evidence for competences difficult to assess with classical assessment methods. Research in performance analytics has to structure and elaborate adequate, holistic, and coherent competency models with appropriate granularity to ease competency mapping, performance forecast and competency gap prediction using AI and other data science approaches. This includes collecting and motivating the update of both generic/European as well as professionspecific/national competency models, adding, for example, a taxonomy of human-robot collaboration skills. Moreover, research actions need to address the collection and annotation of evidence collections (including secondary sources, such as supporting literature, as well as primary sources, such as corpora of workers' performance appraisal files, live-performance observation reports, or interviews with subject matter experts). All stakeholders (i.e., industry, policy makers, and academics) need to agree on the frame of reference for quantifying and benchmarking human performance against underlying competency, linking key business performance indicators with indicators of effective and efficient learning and job execution.
3. New Learning and Training Methods for Performance Augmentation

Research on learning and training methods is required in the domain of knowledge-intensive performance, relevant to the custom and practice of Industry 4.0. These methods have to support the acquisition of competitiveness-enhancing capabilities relating to knowledge-intensive innovation, agility and value-generation, and to raise the Technology Readiness Level (TRL) of all technical components of a 4.0 ecosystem. Existing workplace learning and training technologies (e.g. AR-based) have to be adapted and evaluated in the Industry 4.0 context by respecting the high complexity of CPSs and all their contextual parameters. Personalised performance augmentation technologies can benefit from using contextual data to offer learning experiences that are better adapted to arising learning needs.

\section{Performance Augmentation Technology Impact Assessment} Intelligent assistance systems have substantial potential to relieve professionals from routine work and to facilitate more flexible work organisation and better work life balance. Some of the Performance Augmentation technologies and approaches are expected to positively affect stress levels, ergonomics, usability, user experience, attractiveness of workplaces, job satisfaction, and associated accessibility. Therefore, we recommend conducting more research that investigates the socio-technical impact of technology and approaches on work and life.

\section{CONCLUSIONS}

In order to implement this research roadmap, an interdisciplinary research community needs to be established. The goal has to be to assemble and connect a representative European community of highly placed education and training providers, content developers, systems developers, and scholars in this field. Further, we need to train young talent and next generation leaders in research and industry for Performance Augmentation for Industry 4.0. This will lead to a higher capacity for new R\&D projects, driven by trans-European targeted research groups, to address the central research topics mentioned earlier.

AR in Industry 4.0 is a topic around the globe with Northern America, South Korea, China, Australia, and others working on this. Adding an interdisciplinary R\&D focus on Human Performance Augmentation in Europe will give a competitive advantage that, amongst others, would help to improve productivity costs while error proofing human-robot collaboration.

Finally, the provision of such a technology will help to improve employability in a sustainable way by providing access to better paid jobs. It will also have a positive effect on well being, enabling more (especially young and old) people to keep their jobs through up-skilling, while job performance requirements increase.

\section{REFERENCES}

[1] European Commision. Digitising European Industry - Reaping the full benefits of a Digital Single Market. In Series of Communication from the Commission to the European Parliament, the Council, the European Economic and Social Committee and the Committee of the Regions (COM), 180, 2016. 
[2] Arntz, M., Gregory, T. and Zierahn, U. The Risk of Automation for Jobs in OECD Countries. OECD SEM Working Papers, 189, 2016.

[3] Windberg Baarup, A., Breunig, M., Dufour, M., Gehrig, J., Geldmacher, F. Heberger, M. and Repenning, J. Industry 4.0: How to navigate digitization of the manufacturing sector. McKinsey Digital, 2015.

[4] CIPD. One in four jobs go unfilled due to skills shortage. CIPD, 2016

[5] UKCESS. The UK Commission's Employer Skills Survey 2015. UKCESS, 2016.

[6] Spöttl, G., Gorldt, C., Windelband, L., Grantz, T. and Richter, T. Industrie 4.0 Auswirkungen auf Aus- und Weiterbildung in der M+E Industrie. bayme/vmb, 2016.

[7] WEF. The Global Competitiveness Report: 2016-2017. WEF, 2016.

[8] European Commision. A New Skills Agenda for Europe. Communication from the Commission to the European Parliament, the Council, the European Economic and Social Committee and the Committee of the Regions (COM), 381, 2016.

[9] Hermann, H., Pentek, T. and Otto, B. Design Principles for Industrie 4.0 Scenarios. TU Dortmund, 2015.

[10] BMBF. Industry 4.0 - Innovation für die Produktion von morgen. BMBF: 2015

[11] Lorenz, M., Rüßmann, M., Strack, R., Lasse Lueth, K. and Bolle, M. Man and machine in Industry 4.0, BCG perspectives, 2015.

[12] Perey, C., Wild, F., Helin, K., Janak, M., Davies, P. and Ryan, P. Proc. of Workshop Advanced Manufacturing with Augmented Reality (in conjunction with IEEE International Symposium on Mixed and Augmented Reality - ISMAR2014). In Proceedings of the Proc. of 1st AMAR Workshop, Munich, Germany, Sept. 10-12, 2014.

[13] Aehnelt, M., Pammer-Schindler, V., Klamma, R. and Veas, E. E. Proc. of Workshop Human Computer Interaction Perspectives on Industry 4.0 (at I-KNOW 2016), Graz, Austria, October 18-19, 2016.

14] BMWi. Zukunft der Arbeit in Industrie 4.0. BMWi, 2014

[15] Manyika, J., Chui, M., Bughin, J., Dobbs, R., Bisson, P. and Marrs, A. Disruptive technologies: Advances that will transform life, business, and the global economy McKinsey Global Institute, 2013.

[16] Frey, C. B. and Osborne, M. A. The Future of Employment: How susceptible are jobs to computerisation? University of Oxford, 2013.

[17] Baxter, G., Rooksby, J., Wang, Y. and Khajeh-Hosseini, A. The ironies of automation... still going strong at 30? In: Proceedings of the ECCE 2012, Edinburgh, August 29-31, 2012.

[18] European Commission. Innovation in Digital Manufacturing: Report from the Workshop on Innovation in Digital Manufacturing. EC \& EFFRA, 2015.

[19] Rüßmann, M., Lorenz, M., Gerbert, P., Waldner, M., Justus, J., Engel, P. and Harnisch, M. Industry 4.0: The Future of Productivity and Growth in Manufacturing Industries. BCG, 2015.

[20] Letmathe, P. and Schinner, M. Competence Management in the Age of Cyber Physical Systems. Springer, 2015.

[21] Bäck, C. and Hirsch, J. Thought Piece on the Future of Manufacturing Know How in the Automotive Industry - Case 21. WEF: Manufacturing our Future, 2016.

[22] Pesch, A. Zukunftsbild 'Industrie 4.0'. BMBF, 2014.

[23] Bowles, J. The computerisation of European jobs. Blog post, Bruegel, 2014.

[24] Dispan, J. and Schwarz-Kocher, M. Maschinen- und Anlagenbau in Deutschland. Informationsdienst IMU Institut, 2014

[25] Kagermann, H., Wahlster, W. and Helbig, J. Recommendations for implementing the strategic initiative INDUSTRIE 4.0. Acatech, 2013. 